\title{
Imprecisely Writing About Age Creates More or Less of a Hassle for Editors
}

\author{
Mark B. Mycyk
}

Published online: 22 May 2010

(C) American College of Medical Toxicology 2010

Toxicologists prize precision when evaluating clinical findings and laboratory data. Manuscripts submitted for publication should also meet a toxicologist's high standard for precision. Reports about poisoning often stratify risk by age. Using the word "more" in place of "older" and the word "less" in place of "younger" is frequently done in spoken language, but doing so is technically incorrect. "More" and "less" should only be used to describe approximations in quantity, degree, or amount, but should not be used to describe age.

\section{Example no. 1}

Incorrect: Hospitalization and death from adverse drug events occur most frequently in patients more than 85 years of age.

Correct: Hospitalization and death from adverse drug events occur most frequently in patients older than 85 years age.

\section{Example no. 2}

Incorrect: Almost $90 \%$ of hydrocarbon-related deaths occur in patients less than 5 years of age.

Correct: Almost $90 \%$ of hydrocarbon-related deaths occur in patients younger than 5 years of age.

Even when heard in everyday speech the phrase "more or less" sounds a bit vague, indeterminate, and imprecise. So remember, when precisely defining ages, use the preferred terms "younger" and "older."
M. B. Mycyk ( $\triangle)$

Cook County Hospital, Toxikon Consortium,

1900 West Polk Street, 10th Floor,

Chicago, IL 60612, USA

e-mail: mmycyk@ccbh.org 